\title{
Does Health Literacy Predict Preventive Lifestyle on Metabolic Syndrome? A Population-Based Study in Sarawak Malaysia
}

\author{
S. Froze, M. T. Arif, R. Saimon \\ Department of Community Medicine and Public Health, Faculty of Medicine and Health Sciences, \\ Universiti Malaysia Sarawak, Kota Samarahan, Malaysia \\ Email:samfroze85@yahoo.com
}

How to cite this paper: Froze, S., Arif, M.T. and Saimon, R. (2018) Does Health Literacy Predict Preventive Lifestyle on Metabolic Syndrome? A Population-Based Study in Sarawak Malaysia. Open Journal of Preventive Medicine, 8, 169-182. https://doi.org/10.4236/ojpm.2018.86016

Received: May 8, 2018

Accepted: June 12, 2018

Published: June 15, 2018

Copyright (c) 2018 by authors and Scientific Research Publishing Inc. This work is licensed under the Creative Commons Attribution International License (CC BY 4.0).

http://creativecommons.org/licenses/by/4.0/

\begin{abstract}
Poor health literacy (HL) is a risk factor for developing metabolic syndrome. In Malaysia, about $93 \%$ of adults' population has limited HL-a huge prevalence yet understudied phenomenon. This study aims to determine the predictors of preventive lifestyles on metabolic syndrome among adult population in Sarawak are timely. This was a population-based study, conducted from September 2016 till December 2017 using a multistage stratified sampling method. Health Literacy Scale and Simple Lifestyle Indicator Questionnaire were used to measure health literacy and preventive lifestyles respectively. Analysis of Variance and logistic regression were used to analyze the data. A total of 743 respondents were involved in this study with half of them have acceptable score for health literacy $(\mathrm{M}=46.9, \mathrm{SD}=6.3)$ and good preventive lifestyles $(\mathrm{M}=7.3, \mathrm{SD}=1.4)$. Critical health literacy was a significant influence of preventive lifestyles. The Malay ethnic group has the highest scores for both critical health literacy $[\mathrm{F}(3,739)=17.82, p<0.001]$ and preventive lifestyle compared to other ethnic groups $[\mathrm{F}(3,739)=3.12, p=$ 0.025]. The other Native groups scored the lowest for critical health literacy. Individual with higher score of critical health literacy tend to perform physical activities. Gender, education level, distance of health facilities, critical health literacy and employment status were identified as predictors for preventive lifestyle in this study. Health literacy is a key to preventive lifestyle behaviors in metabolic syndrome among adult population in Sarawak. Future program should focus on improving HL status with specific program targeting ethnic minorities.
\end{abstract}

\section{Keywords}

Health Literacy, Metabolic Syndrome, Preventive Lifestyle, Sarawak 


\section{Introduction}

Globally, the prevalence of metabolic syndrome is ranging from $10 \%$ to $84 \%$, depending on the region, urban or rural environment, sociodemographic composition, and the definition of the syndrome used [1]. Metabolic syndrome (MetS) is a clustering of at least three out five diseases, namely hypertension, glucose intolerance, abdominal obesity, high triglyceride level and low high density lipoprotein (HDL) [2]. These diseases are associated with risk of developing type 2 diabetes and cardiovascular disease [3]. Individuals with metabolic syndrome have five times higher risk developing cardiovascular disease and three times higher risk of developing type 2 diabetes [1]. In Malaysia, the prevalence of metabolic syndrome is $27.5 \%$, the highest among the Indians, Malays and Indigenous population of Sarawak [4]. The prevalence has been increasing due to rapid socioeconomic development which led to sedentary lifestyle. Principally, prevention of MetS involves lifestyle modifications, including intervention on nutritional intake, promotion of physical activity (5) [5]. Evidence suggests that poor health literacy is a risk factor for developing non communicable diseases [6] [7].

The World Health Organization (WHO) defines health literacy skills as "the personal characteristics and social resources needed for individuals and communities to access, understand, appraise and use information and services to make decisions about health" [8]. Nutbeam, D (2000) has suggested the three-level hierarchy of health literacy, consisting of functional, communicative and critical health literacy [9]. The aspect of functional literacy describes a sufficient basic skill possessed by an individual who allows him to read and write. The communicative literacy refers to a more advanced skill possessed by an individual for him or her to participate actively in everyday activities. Critical literacy component refers to a more advanced skill to analyse health related information critically. Coherently, health literacy is one of the social determinants of health which is vital in primary, secondary and tertiary prevention [10]. Poor health literacy is a risk factor for developing metabolic syndrome, type 2 diabetes and cardiovascular disease. Consequently, these diseases contribute to high health system costs. The prevalence of inadequate health literacy was lower among the population of European countries as compared to Asian countries [11]. In Malaysia, about $93 \%$ of adults' population has limited health literacy [12]. Those with adequate health literacy were higher among urbanite (8\%) and Chinese (11\%). This study is therefore aimed to examine the association between health literacy and preventive lifestyle for metabolic syndrome among adults without cardiovascular disease and diabetes from major ethnic groups in Sarawak. Specifically based on the findings in the literature, the following research questions were posed:

1) What are the differences in health literacy and preventive lifestyle on MetS according to sociodemographic variables (gender, ethnicity, marital status, education level, occupation and income status). 
2) What is the magnitude of the association between health literacy and preventive lifestyle behaviours after adjustment for gender, ethnicity, marital status, education level, occupation and income status?

3) What are the predictors of preventive lifestyles for MetS?

\section{Methods}

\subsection{Study Design and Setting}

This was a population-based study utilising multistage stratified sampling design. It was carried out from September 2016 till December 2017 throughout the state of Sarawak, Malaysia. Sarawak is the largest of the fourteen states that form Malaysia. The whole state of Sarawak is divided into 12 divisions with an approximate population of 2.62 million (2013). It is well known for the beautiful flora and fauna with rocky, dense rain-forest and home to diverse ethnic groups. The State is separated from Peninsular Malaysia by the South China Sea and is directly joined to the state of Sabah, Brunei and Kalimantan, Indonesia.

\subsection{Sampling}

Multistage sampling method with ethnicity stratification was applied (Figure 1). Nine out of twelve Divisions were selected according to ethnic distribution. From every Division and District, residential areas were selected. Information on ethnicity distribution was obtained from the administrative Divisional and District Offices. Targeted respondents were above 18 years old with medical and health personnel were excluded to reduce biasness. Based on the prevalence of highly physically active individual in Sarawak (National Health Morbidity Survey 2015), 25\% with design effect of 2 and a precision of 5\%, the calculated sample size was 690 (including 15\% non-response rate). A total of 743 participants took part in this research.

\subsection{Measures}

1) Socio demographic variables include gender, ethnicity, marital status, education level, occupation and income status. This section also measures accessibility of health care facility, co morbidities and family medical history.

2) Health Literacy

A validated Health Literacy Survey (HLS-14) was used to assess health literacy level. It was developed by Suka, M. et al. (2013) [13]. HLS-14 focused on 3 components of HL, namely functional (5 items), communicative (5 items) and for critical (4 items). Participants were required to rate each item on a 5-point Likert scale ranging from 1 (strongly disagree) to 5 (strongly agree). Functional HL focused on the adequacy of basic skills in reading and writing. The communicative section was intended to assess a more progressive skill on the ability of the participants to extract essential information and to obtain meaning from diverse forms of communication. Additionally, respondents were assessed on their capability to apply current information to the change of circumstances. 


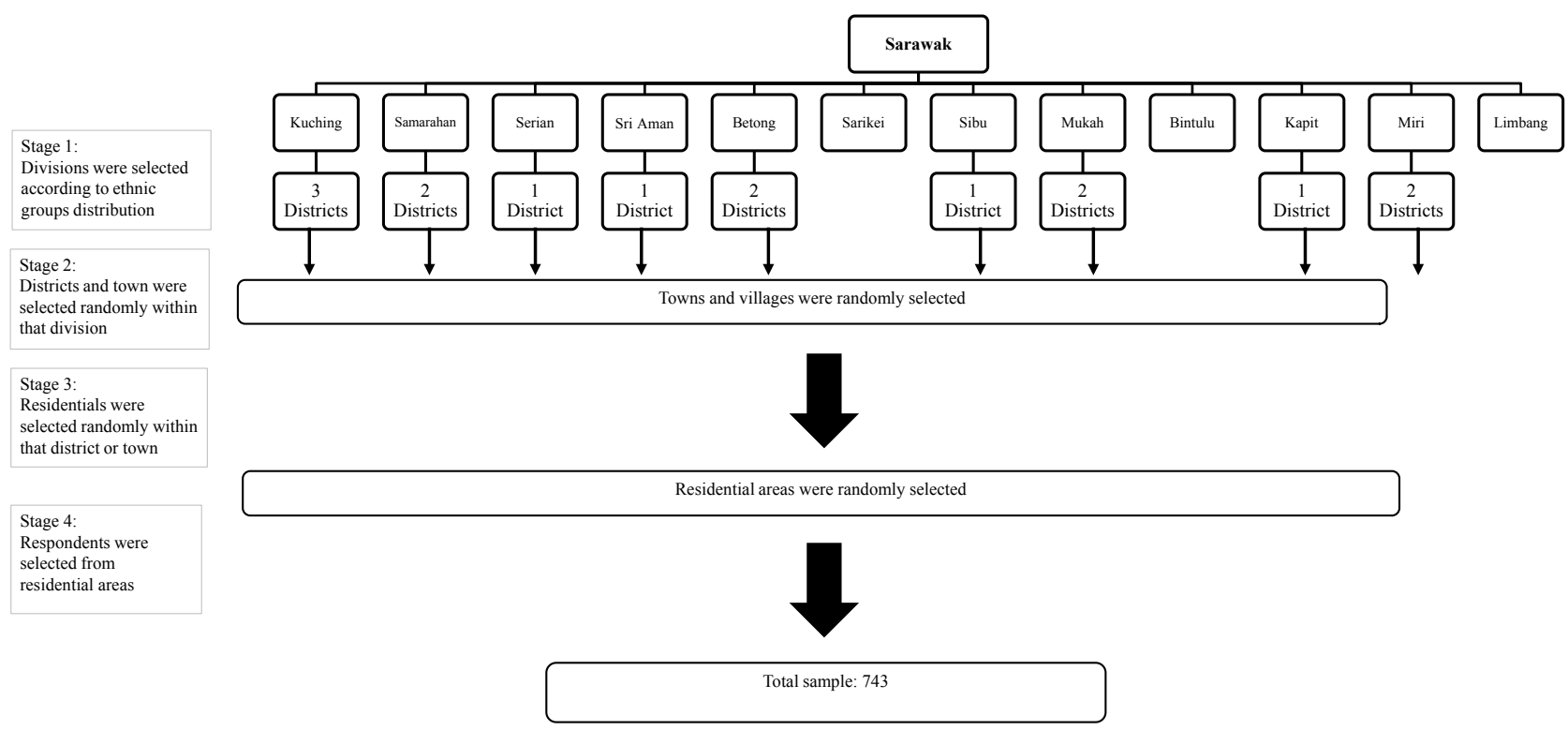

Figure 1. Diagram of multistage sampling across the State of Sarawak.

Lastly, the critical health literacy component was designed to evaluate a more advanced skill, whether an individual can analyse information critically.

3) Knowledge of metabolic syndrome

This construct contained 20 questions, to measure the knowledge of respondents specifically on metabolic syndrome and was adopted from Yahia N. et al., (2014) [14]. For every question, the respondents need to select one correct answer out of 3 options (True, False or Don't Know).

4) Preventive/Healthy lifestyle against metabolic syndrome

Lifestyle of participants was assessed with Simple Lifestyle Indicator Questionnaire (SLIQ) which was developed by Godwin et al. (2008) [15]. It consists of 5 domains with a total of 12 questions. Three questions on frequency of consumption of leafy green vegetables, fruits, and high fibre cereals or grains. Three questions assess the practice of various light, moderate, and vigorous physical activities. Three questions measure alcohol consumption followed by two questions on smoking history, and one on stress levels. Activity, Diet and Stress were assessed in the form of Likert scales. For alcohol consumption, respondents were asked on the total number of drinks consumed per week. The smoking score were determined based these categories: current, past, or non-smoker. The overall SLIQ score is based on the 5 category scores to provide equal weighting for every component. Each domain has a category score of 0 , 1, or 2, so overall SLIQ scores can range from 0 to 10 . Higher score indicates healthier lifestyle.

\subsection{Ethical Consideration}

Approval to conduct this research was obtained from Medical Research Ethics Committee (MREC) of Universiti Malaysia Sarawak (UNIMAS). Participation in this study was voluntary. Written Informed Consent was obtained from participants and confidentiality of information was guaranteed. 


\subsection{Statistical Analysis}

The collected data were coded and analysed using Statistical Package for Social Science (SPSS) version 23. All the data were being checked thoroughly and cleaned prior to analysis. Incomplete data were analysed using maximum likelihood estimation method. Independent $t$ test and anova was applied to determine the differences in means between groups. Multiple logistic regression was run to predict factors influencing lifestyle behaviour.

\section{Results}

\subsection{Characteristics of Respondents}

A total of 743 respondents were involved in this study. The calculated mean age was $37.3(\mathrm{SD}=14.1)$ years old. The majority of participants were female $(53 \%)$, married (63\%) and obtained secondary education (55\%) (Table 1). The four ethnic groups were Malay (20\%), Iban (20\%), Chinese (24\%) and other Native groups (36\%). Almost half of them were employed (47\%) and the remaining were self employed (23\%) and unemployed (30\%). A total of $73 \%$ of the participants were staying within $10 \mathrm{~km}$ from the nearest health care facilities. A total of $69 \%$ of the study participants were without any co morbidities and $23 \%$ of them had first degree relative with history of heart diseases. For health literacy component, more than half of the participants obtained adequate score in functional (58\%), communicative (52\%) and critical health literacy (56.\%). Half of the respondents (51\%) reported to have good preventive lifestyles.

Female respondents $(14.9+/-2.78)$ scored better than male $(14.3+/-3.03)$ for critical health literacy $(\mathrm{t}(741)=-2.63, p=0.018)$. They also have better preventive lifestyle against metabolic syndrome $(7.63+/-1.18)$ than the male respondents $(6.85+/-1.54)$, [t $(741)=7.78, p<0.001]$. Malays obtained the highest scores for all three health literacy components compared to other ethnic groups, functional $[\mathrm{F}(3,739)=8.79, p<0.001]$, communicative $[\mathrm{F}(3,739)=15.69, p<$ $0.001]$ and critical $[\mathrm{F}(3,739)=17.82, p<0.001]$. They also have the highest score for preventive lifestyle $[\mathrm{F}(3,739)=3.12, p=0.025]$. The other native groups scored the lowest health literacy. There was a significant correlation between health literacy and preventive lifestyle among participants $(r=0.10, n=$ $743, p=0.006)$. Individual with higher score of health literacy tend to do physical activities (Table 2). Participants with tertiary education $[\mathrm{F}(3,739)=2.345, p$ $=0.072]$ and without own income $(7.6+/-1.21),[\mathrm{t}(741)=-4.076, p=0.002]$ were more likely to practise healthy lifestyle.

\subsection{Predictors of Preventive Lifestyle against Metabolic Syndrome}

A binary regression model was performed to determine the predictors of Healthy lifestyle among different ethnic groups in Sarawak (Table 3). Simple Lifestyle Indicator Questionnaire (dichotomous) was the dependent variable. It was categorized into lower and higher score. Selected variables on socio 
Table 1. Socio demographic characteristic of study participants.

\begin{tabular}{|c|c|c|c|c|c|}
\hline Characteristics & n (\%) & $\begin{array}{c}\text { Functional } \\
\text { HL }\end{array}$ & $\begin{array}{c}\text { Communicative } \\
\text { HL }\end{array}$ & $\begin{array}{c}\text { Critical HL } \\
\text { Mean }\end{array}$ & $\begin{array}{r}\text { Preventive } \\
\text { Lifestyle }\end{array}$ \\
\hline & & $\begin{array}{c}\text { Mean } \\
\text { score }(S D)\end{array}$ & Mean score(SD) & $\begin{array}{c}\text { Mean } \\
\text { score(SD) }\end{array}$ & $\begin{array}{c}\text { Mean } \\
\text { score }(\mathrm{SD})\end{array}$ \\
\hline \multicolumn{6}{|l|}{ Gender } \\
\hline Male & $350(47)$ & $14.4(2.7)$ & $17.6(3.7)$ & $14.3(3.0)$ & $6.9(1.5)$ \\
\hline Female & $393(53)$ & $14.0(2.7)$ & $18.2(3.4)$ & $14.9(2.8)$ & $7.6(1.2)$ \\
\hline$P$ value & & ${ }^{1} 0.995$ & ${ }^{1} 0.360$ & ${ }^{1} 0.018$ & ${ }^{1}<0.001$ \\
\hline \multicolumn{6}{|l|}{ Age group } \\
\hline Young adults (18 - 25) & $191(26)$ & $14.4(2.8)$ & $17.7(3.8)$ & $14.3(3.2)$ & $7.4(1.4)$ \\
\hline Adulthood (26 - 40) & $282(38)$ & $14.1(2.6)$ & $17.8(3.5)$ & $14.6(2.8)$ & $7.32(1.4)$ \\
\hline Middle age (40-60) & $212(29)$ & $14.1(2.7)$ & $18.1(3.6)$ & $14.8(2.9)$ & $7.1(1.4)$ \\
\hline Old age $(>60)$ & $58(8)$ & $14.4(3.0)$ & $18.3(2.7)$ & $15.0(2.5)$ & $7.2(1.5)$ \\
\hline$P$ value & & ${ }^{2} 0.899$ & ${ }^{2} 0.104$ & ${ }^{2} 0.011$ & ${ }^{2} 0.109$ \\
\hline \multicolumn{6}{|l|}{ Marital status } \\
\hline Married & $469(63)$ & $14.4(2.8)$ & $18.2(3.3)$ & $14.7(2.8)$ & $7.3(1.4)$ \\
\hline Not married & $245(33)$ & $13.6(2.4)$ & $17.4(3.9)$ & $14.5(3.0)$ & $7.3(1.4)$ \\
\hline Divorced & $29(4)$ & $14.5(2.7)$ & $18.1(3.7)$ & $14.3(3.4)$ & $6.8(1.5)$ \\
\hline$P$ value & & ${ }^{2} 0.001$ & ${ }^{2} 0.011$ & ${ }^{2} 0.587$ & ${ }^{2} 0.182$ \\
\hline \multicolumn{6}{|l|}{ Ethnic groups } \\
\hline Malay & $150(20.2)$ & $15.2(2.91)$ & $19.0(3.14)$ & $15.6(2.4)$ & $7.4(1.3)$ \\
\hline Iban & $149(20.1)$ & $14.1(2.47)$ & $18.1(3.51)$ & $14.9(2.74)$ & $7.2(1.4)$ \\
\hline Chinese & $175(23.6)$ & $14.0(2.44)$ & $18.4(3.17)$ & $15.0(3.00)$ & $7.4(1.3)$ \\
\hline \multirow[t]{2}{*}{ Other Native groups } & $269(36.2)$ & $13.8(2.79)$ & $16.8(3.75)$ & $13.7(2.94)$ & $7.1(1.6)$ \\
\hline & & ${ }^{2}<0.001$ & ${ }^{2}<0.001$ & ${ }^{2}<0.001$ & ${ }^{2} 0.025$ \\
\hline \multicolumn{6}{|l|}{ Employment status } \\
\hline Employed & $350(47.1)$ & $14.1(2.65)$ & $18.1(3.6)$ & $14.9(2.9)$ & $7.1(1.5)$ \\
\hline Self employed & $167(22.5)$ & $14.5(2.78)$ & $18.0(3.1)$ & $14.8(2.6)$ & $7.2(1.3)$ \\
\hline \multirow[t]{2}{*}{ Unemployed } & $226(30.4)$ & $14.2(2.77)$ & $17.5(3.8)$ & $14.1(3.1)$ & $7.6(1.2)$ \\
\hline & & ${ }^{2} 0.300$ & ${ }^{2} 0.186$ & ${ }^{2} 0.003$ & ${ }^{2} 0.009$ \\
\hline \multicolumn{6}{|l|}{ Education level } \\
\hline No formal education & $63(9)$ & $15.5(2.9)$ & $17.6(3.4)$ & $13.7(3.2)$ & $6.8(1.6)$ \\
\hline Primary education & $126(17)$ & $15.1(2.9)$ & $17.7(3.4)$ & $14.3(2.9)$ & $7.3(1.4)$ \\
\hline Secondary education & $405(55)$ & $13.9(2.7)$ & $18.1(3.7)$ & $14.8(2.8)$ & $7.3(1.4)$ \\
\hline Tertiary education & $149(20)$ & $13.5(2.3)$ & $17.8(3.4)$ & $14.9(3.1)$ & $7.3(1.4)$ \\
\hline
\end{tabular}




\section{Continued}

\begin{tabular}{|c|c|c|c|c|c|}
\hline & & ${ }^{2}<0.001$ & ${ }^{2} 0.595$ & ${ }^{2} 0.016$ & ${ }^{2} 0.072$ \\
\hline \multicolumn{6}{|l|}{ Income status } \\
\hline With own income & $517(70)$ & $14.2(2.7)$ & $18.1(3.5)$ & $14.9(2.8)$ & $7.1(1.5)$ \\
\hline \multirow{2}{*}{$\begin{array}{l}\text { Without own } \\
\text { income }\end{array}$} & $226(30)$ & $14.2(2.8)$ & $17.5(3.8)$ & $14.1(3.1)$ & $7.6(1.2)$ \\
\hline & & ${ }^{1} 0.552$ & ${ }^{1} 0.068$ & ${ }^{1} 0.066$ & ${ }^{1} 0.002$ \\
\hline \multicolumn{6}{|l|}{$\begin{array}{l}\text { Distance to nearest } \\
\text { Health care facility }\end{array}$} \\
\hline Less than $5 \mathrm{~km}$ & $279(38)$ & $13.7(2.8)$ & $18.0(4.0)$ & $14.6(3.1)$ & $7.1(1.4)$ \\
\hline $5-10 \mathrm{~km}$ & $260(35)$ & $14.4(2.6)$ & $17.4(3.5)$ & $14.2(3.1)$ & $7.2(1.5)$ \\
\hline \multirow[t]{2}{*}{ More than $10 \mathrm{~km}$} & $200(27)$ & $14.5(2.8)$ & $18.5(2.9)$ & $15.2(2.3)$ & $7.4(1.3)$ \\
\hline & & ${ }^{2} 0.002$ & ${ }^{2} 0.005$ & ${ }^{2} 0.001$ & ${ }^{2} 0.173$ \\
\hline
\end{tabular}

$\mathrm{P}<0.05,{ }^{1} \mathrm{p}$-value from independent $\mathrm{t}$-test, ${ }^{2} \mathrm{p}$-value from one-way anova.

Table 2. Comorbidities, Health Literacy components and Health Knowledge.

\begin{tabular}{|c|c|c|c|c|c|c|}
\hline \multirow{2}{*}{ Characteristics } & \multirow{2}{*}{$\mathrm{n}(\%)$} & \multirow{2}{*}{ Mean (SD) } & \multirow{2}{*}{$\begin{array}{l}\text { Healthy Lifestyle } \\
\text { Mean score(SD) }\end{array}$} & \multicolumn{2}{|c|}{$95 \%$ CI } & \multirow{2}{*}{$p$ value } \\
\hline & & & & lower & upper & \\
\hline Co morbidities & & & & & & 0.460 \\
\hline Without & $516(69)$ & & $7.3(1.4)$ & 7.16 & 7.41 & \\
\hline With & $227(31)$ & & $7.2(1.4)$ & 7.01 & 7.39 & \\
\hline $\begin{array}{c}\text { First degree relative with } \\
\text { Heart diseases }\end{array}$ & & & & & & 0.588 \\
\hline Yes & $173(23)$ & & $7.2(1.4)$ & 7.03 & 7.46 & \\
\hline No & $570(77)$ & & $7.3(1.4)$ & 7.15 & 7.38 & \\
\hline Functional Health Literacy & & $14.1(2.72)$ & & & & 0.662 \\
\hline Lower score & $310(42)$ & & $7.3(1.5)$ & 7.15 & 7.47 & \\
\hline Higher score & $433(58)$ & & $7.2(1.4)$ & 7.09 & 7.35 & \\
\hline $\begin{array}{c}\text { Communicative Health } \\
\text { Literacy }\end{array}$ & & $17.9(3.56)$ & & & & 0.278 \\
\hline Lower score & $358(48)$ & & $7.1(1.4)$ & 6.99 & 7.28 & \\
\hline Higher score & $385(52)$ & & $7.4(1.4)$ & 7.23 & 7.52 & \\
\hline Critical Health Literacy & & $14.6(2.91)$ & & & & 0.026 \\
\hline Lower score & $331(45)$ & & $14.6(2.91)$ & 6.87 & 7.20 & \\
\hline Higher score & $412(56)$ & & $7.4(1.3)$ & 7.32 & 7.56 & \\
\hline Health Knowledge & & $6.5(3.98)$ & & & & 0.765 \\
\hline Lower score & $312(42)$ & & $7.4(1.4)$ & 7.05 & 7.31 & \\
\hline Higher score & $431(58)$ & & $7.2(1.4)$ & 7.21 & 7.52 & \\
\hline
\end{tabular}

$\mathrm{P}<0.05, \mathrm{p}$-value from independent t-test.

demographic characteristics, health related characteristics, health literacy and knowledge were assigned as the independent variables. Univariate analysis had shown that there were several factors which has significant relationship with preventive activity against metabolic syndrome, $\chi^{2}(8)=84.19, p<0.001$. Female respondents were 2.86 times more likely to practice better preventive behavior against metabolic syndrome ( $\mathrm{p}$ value $<0.001,95 \% \mathrm{CI}=2.056,3.965$ ) compared to their male counterpart. Respondents with tertiary education were 2.21 times 
Table 3. Multivariate analysis of preventive lifestyle against metabolic syndrome.

\begin{tabular}{|c|c|c|c|c|}
\hline \multirow{2}{*}{ Characteristics } & \multirow{2}{*}{ Adjusted OR } & \multicolumn{2}{|c|}{$95 \% \mathrm{CI}$} & \multirow{2}{*}{$p$-value } \\
\hline & & Lower & Upper & \\
\hline \multicolumn{5}{|l|}{ Gender } \\
\hline Male & - & - & - & - \\
\hline Female & 2.796 & 2.018 & 3.875 & $<0.001$ \\
\hline \multicolumn{5}{|l|}{ Education } \\
\hline No formal education & - & & & \\
\hline Primary education & 1.314 & 0.685 & 2.521 & 0.411 \\
\hline Secondary education & 1.490 & 0.841 & 2.637 & 0.172 \\
\hline Tertiary education & 2.208 & 1.166 & 4.183 & 0.015 \\
\hline \multicolumn{5}{|c|}{ Distance of Health facilities } \\
\hline Less than $5 \mathrm{~km}$ & - & - & - & - \\
\hline $5-10 \mathrm{~km}$ & 1.734 & 1.205 & 2.495 & 0.003 \\
\hline More than $10 \mathrm{~km}$ & 1.984 & 1.337 & 2.945 & 0.001 \\
\hline \multicolumn{5}{|l|}{ Critical Health Literacy } \\
\hline Lower score & - & - & - & - \\
\hline Higher score & 1.445 & 1.056 & 1.978 & 0.021 \\
\hline \multicolumn{5}{|l|}{ Employment } \\
\hline Employed & - & - & - & - \\
\hline Unemployed & 1.520 & 1.061 & 2.177 & 0.022 \\
\hline
\end{tabular}

$\mathrm{n}=743$. Hosmer and Lemeshow Test $\mathrm{p}$-value $=4.924>0.05 ; \mathrm{CI}=$ Confidence Interval; OR = Odd Ratio; ${ }^{a}$ Multiple Logistic Regression (no multicollinearity, assumptions were all met).

more likely to practice better preventive care against metabolic syndrome than respondents without formal education and those who obtained primary and secondary education. Participants who reside more than $10 \mathrm{~km}$ from the nearest health care facilities were more likely to have better lifestyle compared to those $(\mathrm{OR}=1.98, \mathrm{p}$ value $=0.001,95 \% \mathrm{CI}=1.337,2.945)$. For health literacy, the critical component was a significant factor to predict preventive behavior against metabolic syndrome. Individual with high score of critical health literacy was 1.45 times more likely to have better lifestyle to prevent metabolic syndrome. This model comprises of five independent variables explained between $11 \%$ (Cox and Snell R square) and 14.4\% (Nagelkerke $\mathrm{R}^{2}$ ) of the variance in the level of satisfaction. This model correctly classified $65 \%$ of the cases. The goodness of fit indices was not statistically significant [Chi square ( $\mathrm{df})=4.924(8) ; \mathrm{p}>0.05$ ] which indicated good fitted model.

\section{Discussion}

This study examined what are the numerous factors that affect and contribute to 
preventive behaviour against metabolic syndrome in Malaysia. It has been well established that metabolic syndrome is a lifestyle related disease. Healthy lifestyle remains the most effective measure to avoid non-communicable diseases [5] [16]. Simple Lifestyle Indicator Questionnaire provides complete assessment of healthy lifestyle. Only a total of $50.5 \%$ of the respondents were being categorised as practising healthy lifestyle. This finding was considered low with the increasing trend of non-communicable diseases worldwide [17]. Worldwide leading cause of death for the past 15 years has been ischemic heart diseases. Similar scenario was reported in Malaysia by Department of Statistics Malaysia in 2017 that the principal cause of death among Malaysian was ischemic heart diseases [18]. Moreover, two of the top three causes of death namely ischemic heart disease and stroke were complications of non-communicable diseases. Lifestyle modification therapy has been used in Public Health to prevent and treat diseases that make up metabolic syndrome. Reversal of metabolic syndrome will improve individual's quality of life and prolong lifespan. Females were reported to be more proactive than male participants in term of lifestyle against metabolic syndrome. Similar finding was also reported in Malaysia [4]. In contrast to our findings, one study in Japan by Kudo, N., et al. (2016) which reported the men were more likely to engage in healthy lifestyle behaviours than women [19]. It is important for both genders to participate in healthy lifestyle with a stronger emphasis on women as several studies postulated that female has higher risk of increased prevalence in developing metabolic syndrome [20] [21] [22].

Our study proved that education status is one of the essential factors for an individual to embark on healthy lifestyle behaviours. Respondents with tertiary education tend to have better regimes to prevent non-communicable like metabolic syndrome. This finding demonstrated the importance of education as one of the health determinants. Cheah, Y. K. (2014) in their study on report of third National Health and Morbidity Survey Malaysia suggested otherwise [23]. The author postulated that, individual with tertiary education were less likely to be physically active. Another study in United State of America supported our finding on education status. They reported that, the higher the accomplishment, the healthier the lifestyle [24]. It is also interesting to note that distance of the nearest health care facilities from residential area was identified as one of the significant factor influencing healthy behaviour among the community. We reported that those staying furthest from health care facility tend to adopt better preventive behaviours against metabolic syndrome. The mobile health services, flying doctor service and village health promoter programs has long been established in the state of Sarawak to cater for the less accessible area [25]. After adjusting for age and gender, Malays have the highest scores for both critical health literacy component and preventive lifestyle compared to the other ethnic groups. The other native groups scored the lowest for both critical health literacy and healthy lifestyle. There was a significant correlation between health literacy and preventive lifestyle among participants. Individual with higher score of health literacy 
tend to do physical activities. Critical component of HL was statistically significant in predicting healthy lifestyle among the respondents. Critical literacy is defined as a more progressive skill to analyse health related information critically and the ability to use this information to exercise better control over life events and situations [9]. This definition explained the outcome of our study, the higher the critical Health Literacy score, the better the preventive lifestyle against metabolic syndrome. Ability to seek and understand health related information is incomplete if an individual has no skill to put to practical use. Existing literatures support the notion-individual with sufficient health literacy were less likely to be indulged in risky behaviour compared to those with inadequate health literacy level [19] [26] [27]. It is important to assess the lifestyle behaviour of the community to identify what and where are the gaps. This gender discrepancy and differences between ethnic group need to be further investigated. Culturally appropriate intervention strategies should be implemented. It will be ideal to integrate the teaching on lifestyle related diseases into the education system. This is one area we can explore for us to nurture the upcoming generation with health literacy skill for them to embark on healthy lifestyle in the future. Similar scenario can be observed in health facility setting. One study conducted in Denmark support this finding. Friis, K. et al. (2016) studied the relationship between Health literacy and health behaviour among people with diabetes in Denmark. From their analysis, they discovered that respondents with difficulties to understand health information were more likely to be physically inactive [28].

In this study, the unemployed individuals were reported to have less adverse lifestyle than the employed participants. Work related stress is not a new issue as it has been studied extensively in Malaysia and worldwide. It can be observed among various type of working groups. The World Health Organisation defines healthy workplace as one in which workers and managers collaborate to use a continual improvement process to protect and promote the health, safety and wellbeing of all workers and the sustainability of the workplace. An ideal workplace will protect its employees from physical and psychosocial hazards [29]. In addition to that, it will provide resources to maintain personal health and opportunity to be involved in activities which support the social and physical wellbeing of a community in which it operates. The lack of healthy components in workplace can risk factors for adverse lifestyle. An unhealthy workplace itself can be hazard for developing non-communicable diseases according to findings by several studies [30] [31]. Many individuals were still unaware of the important relationship between healthy lifestyle and chronic disease [32]. In our study, level of knowledge on metabolic disorder did not affect its preventive lifestyle. This is one of the crucial areas where intervention can be considered. In contrast with one study conducted in Kelantan whereby the researchers reported that health knowledge affects the practice of healthy behaviour [33]. Knowledge on the disease itself is insufficient without the ability to critically appraise the existing information. Community should be educated on chronic diseases from the early age. Learning on the disease itself and its prevention can be beneficial 
for the upcoming generation. Our study would be able to provide insight into lack of education to create awareness on healthy lifestyle. Coherently, education status has also been linked with childhood obesity [34]. The 2011-2012 National Survey of Children's Health in USA indicated that unhealthy habit among adolescent was associated with poor education level. The prevalence of unhealthy habit among children is on the rise [35] [36] [37]. Despite the call to clinicians to prescribe physical activity and modification on other sedentary habits, the component of healthy behaviour should be nurtured since childhood.

Every limitation in this study warrant explanations. Cross-sectional study only allows us to collect independent and outcome variables simultaneously. This resulted in association can be identified but causality could not be inferred. Secondly, we did not include foreigners in our research. We should not rule out the possibilities of the influx of foreign workers into Malaysia also can affect the general health status of our community. The main strength of study was, being a community based participatory research, we managed to include all the major ethnic groups in Sarawak. Thus, the multistage stratified sampling methods will ensure each subgroup within the population receives proper representation within the sample. In this case, we applied ethnic stratification. Furthermore, the findings of this study determined the status of the general population instead of population utilising health care facilities. Hence, its outcome can be used for primordial and primary prevention. Another core strength of this study was the data collection method. Interviewer assisted questionnaire technique enables accurate screening and avoids false information.

\section{Conclusion}

The overall prevalence of adequate preventive lifestyle against metabolic syndrome is still low and it increases with critical health literacy. Thus, health literacy is key to practice healthy behaviours among adult population in Sarawak. Health related education and information should be started early in life and can be integrated in school health curriculum. The element of critical health literacy should be emphasized as functional and communicative health literacy is not sufficient. Most importantly, it must be culturally adaptive Protective lifestyle is proven to be effective to combat metabolic syndrome but unfortunately not practiced adequately.

\section{Acknowledgements}

We gratefully acknowledged all the participants of this study for their generous cooperation. Special thanks to Department of Community Medicine and Public Health of Universiti Malaysia Sarawak for the enormous contribution in making this research a success. Our thanks also go to all the research assistants involved in this research.

\section{Funding}

This work was supported by Institute of Borneo Studies of Universiti Malaysia 
Sarawak (Unimas) with the reference number of F05/NRC/1636/2017.

\section{Competing Interests}

The authors declare that they have no competing interests.

\section{References}

[1] Kaur, J. (2014) A Comprehensive Review on Metabolic Syndrome. Cardiology Research and Practice, 2014, Article ID: 943162. https://doi.org/10.1155/2014/943162

[2] American Heart Association (2015) What Is Metabolic Syndrome? https://www.heart.org/idc/groups/heart-public/@wcm/@hcm/documents/download able/ucm_300322.pdf

[3] Alberti, K., Eckel, R., Grundy, S., Zimmet, P., Cleeman, J. and Donato, K., et al. (2010) Harmonizing the Metabolic Syndrome: A Joint Interim Statement of the International Diabetes Federation Task Forceon Epidemiology and Prevention; National Heart, Lung, and Blood Institute; American Heart Association; World Heart Federation; International Atherosclerosis Society; and International Association for the Study of Obesity. Obesity and Metabolism, No. 1, 63. https://doi.org/10.14341/2071-8713-5281

[4] Rampal, S., Mahadeva, S., Guallar, E., Bulgiba, A., Mohamed, R. and Rahmat, R., et al. (2012) Ethnic Differences in the Prevalence of Metabolic Syndrome: Results from a Multi-Ethnic Population-Based Survey in Malaysia. Plos ONE, 7, e46365. https://doi.org/10.1371/journal.pone.0046365

[5] Van Wormer, J., Boucher, J., Sidebottom, A., Sillah, A. and Knickelbine, T. (2017) Lifestyle Changes and Prevention of Metabolic Syndrome in the Heart of New Ulm Project. Preventive Medicine Reports, 6, 242-245.

https://doi.org/10.1016/j.pmedr.2017.03.018

[6] Qin, L. and Xu, H. (2016) A Cross-Sectional Study of the Effect of Health Literacy on Diabetes Prevention and Control among Elderly Individuals with Prediabetes in Rural China. BMJ Open, 6, e011077. https://doi.org/10.1136/bmjopen-2016-011077

[7] Eltayeb, R., Salmiah, M.S. and Suriani, I. (2016) Association of Health Literacy with Obesity and Overweight among Arabic Secondary School Students in Kuala Lumpur and Putrajaya, Malaysia. International Journal of Public Health and Clinical Sciences, 3, 110-121.

[8] Osborne, R., Batterham, R. and Beauchamp, A. (2014) Health Literacy Toolkit. National Network of Libraries of Medicine Southeastern, Atlantic Region.

[9] Nutbeam, D. (2000) Health Literacy as a Public Health Goal: A Challenge for Contemporary Health Education and Communication Strategies into the 21st Century. Health Promotion International, 15, 259-267. https://doi.org/10.1093/heapro/15.3.259

[10] Freedman, D., Bess, K., Tucker, H., Boyd, D., Tuchman, A. and Wallston, K. (2009) Public Health Literacy Defined. American Journal of Preventive Medicine, 36, 446-451. https://doi.org/10.1016/j.amepre.2009.02.001

[11] Kickbusch, I., Pelikan, J., Apfel, F. and Tsouros, A (2013) Health Literacy: The Solid Facts. WHO Regional Office for Europe, Copenhagen, 7-8.

[12] Institute for Public Health (2015) National Health and Morbidity Survey 2015 (NHMS 2015). Vol. II: Non-Communicable Diseases, Risk Factors \& Other Health Problems. Ministry of Health (Vol. II).

[13] Suka, M., Odajima, T., Kasai, M., Igarashi, A., Ishikawa, H., Kusama, M., Sugimori, 
H., et al. (2013) The 14-Item Health Literacy Scale for Japanese Adults (HLS-14). Environmental Health and Preventive Medicine, 18, 407-415. https://doi.org/10.1007/s12199-013-0340-Z

[14] Yahia, N., Brown, C., Rapley, M. and Chung, M. (2014) Assessment of College Students' Awareness and Knowledge about Conditions Relevant to Metabolic Syndrome. Diabetology \& Metabolic Syndrome, 6, 111. https://doi.org/10.1186/1758-5996-6-111

[15] Godwin, M., Streight, S., Dyachuk, E., Van Den Hooven, E.C., Ploemacher, J., Seguin, R. and Cuthbertson, S. (2008) Testing the Simple Lifestyle Indicator Questionnaire: Initial Psychometric Study. Canadian Family Physician, 54, 76-77.

[16] Dunkley, A., Davies, M., Stone, M., Taub, N., Troughton, J., Yates, T. and Khunti, K. (2011) The Reversal Intervention for Metabolic Syndrome (TRIMS) Study: Rationale, Design, and Baseline Data. Trials, 12, 107. https://doi.org/10.1186/1745-6215-12-107

[17] WHO (2014) Global Status Report on Noncommunicable Diseases 2014. World Health, 176.

[18] DOSM (2017) Department of Statistics Malaysia Press Release. Department of Statistics Malaysia, 5-9.

[19] Kudo, N., Yokokawa, H., Fukuda, H., Hisaoka, T., Isonuma, H. and Naito, T. (2016) Analysis of Associations between Health Literacy and Healthy Lifestyle Characteristics among Japanese Outpatients with Lifestyle-Related Disorders. Journal of General and Family Medicine, 17, 299-306. https://doi.org/10.14442/jgfm.17.4_299

[20] Bentley-Lewis, R., Koruda, K. and Seely, E. (2007) The Metabolic Syndrome in Women. Nature Clinical Practice. Endocrinology \& Metabolism, 3, 696-704. https://doi.org/10.1038/ncpendmet0616

[21] Ranasinghe, P., Mathangasinghe, Y., Jayawardena, R., Hills, A. and Misra, A. (2017) Prevalence and Trends of Metabolic Syndrome among Adults in the Asia-Pacific Region: A Systematic Review. BMC Public Health, 17, 101. https://doi.org/10.1186/s12889-017-4041-1

[22] Yu, S., Guo, X., Yang, H., Zheng, L. and Sun, Y. (2014) An Update on the Prevalence of Metabolic Syndrome and Its Associated Factors in Rural Northeast China. BMC Public Health, 14, 877. https://doi.org/10.1186/1471-2458-14-877

[23] Cheah, Y.K. and Poh, B.K. (2014) The Determinants of Participation in Physical Activity in Malaysia. Osong Public Health and Research Perspectives, 5, 20-27. https://doi.org/10.1016/j.phrp.2013.12.002

[24] Hahn, R. and Truman, B. (2015) Education Improves Public Health and Promotes Health Equity. International Journal of Health Services, 45, 657-678. https://doi.org/10.1177/0020731415585986

[25] Koshy, R., Noh, K.M., Juval, K., Agamutu, K. and Nazimin Shamsuddin, M. (2013) Flying Doctor Service in East Malaysia. The European Journal of Public Health, 23, 10-11. https://doi.org/10.1093/eurpub/ckt123.184

[26] Liu, Y., Liu, L., Li, Y. and Chen, Y. (2015) Relationship between Health Literacy, Health-Related Behaviors and Health Status: A Survey of Elderly Chinese. International Journal of Environmental Research and Public Health, 12, 9714-9725. https://doi.org/10.3390/ijerph120809714

[27] Fernandez, D.M., Larson, J.L. and Zikmund-Fisher, B.J. (2016) Associations between Health Literacy and Preventive Health Behaviors among Older Adults: Findings from the Health and Retirement Study. BMC Public Health, 16, 596. https://doi.org/10.1186/s12889-016-3267-7 
[28] Friis, K., Vind, B.D., Simmons, R.K. and Maindal, H.T. (2016) The Relationship between Health Literacy and Health Behaviour in People with Diabetes: A Danish Population-Based Study. Journal of Diabetes Research, 2016, Article ID: 7823130. https://doi.org/10.1155/2016/7823130

[29] WHO (2010) Healthy Workplaces: A Model for Action. WHO, Geneva, 1-32.

[30] Kivimäki, M., Head, J., Ferrie, J.E., Shipley, M.J., Brunner, E., Vahtera, J. and Marmot, M.G. (2006) Work Stress, Weight Gain and Weight Loss: Evidence for Bidirectional Effects of Job Strain on Body Mass Index in the Whitehall II Study. International Journal of Obesity, 30, 982-987. https://doi.org/10.1038/sj.ijo.0803229

[31] Rodriguez-Fernandez, R., Rahajeng, E., Viliani, F., Kushadiwijaya, H., Amiya, R.M. and Bangs, M.J. (2015) Non-Communicable Disease Risk Factor Patterns among Mining Industry Workers in Papua, Indonesia: Longitudinal Findings from the Cardiovascular Outcomes in a Papuan Population and Estimation of Risk (COPPER) Study. Occupational and Environmental Medicine, 72, 728-735. https://doi.org/10.1136/oemed-2014-102664

[32] Song, Y., Ma, W., Yi, X., Wang, S., Sun, X., Tian, J., et al. (2013) Chronic Diseases Knowledge and Related Factors among the Elderly in Jinan, China. PLOS ONE, 8 , e68599. https://doi.org/10.1371/journal.pone.0068599

[33] Yahya, R., Muhamad, R. and Yusoff, H.M. (2012) Association between Knowledge, Attitude and Practice on Cardiovascular Disease among Women in Kelantan, Malaysia. International Journal of Collaborative Research on Internal Medicine and Public Health, 4, 1507-1523

[34] Carey, F., Singh, G., Brown III, H. and Wilkinson, A. (2015) Educational Outcomes Associated with Childhood Obesity in the United States: Cross-Sectional Results from the 2011-2012 National Survey of Children's Health. International Journal of Behavioral Nutrition and Physical Activity, 12, S3. https://doi.org/10.1186/1479-5868-12-S1-S3

[35] Nascente, F., Jardim, T., Peixoto, M., Carneiro, C., Mendonça, K., Póvoa, T., et al. (2016) Sedentary Lifestyle and Its Associated Factors among Adolescents from Public and Private Schools of a Brazilian State Capital. BMC Public Health, 16, 1177. https://doi.org/10.1186/s12889-016-3836-9

[36] Roberts, J.D., Rodkey, L., Ray, R., Knight, B. and Saelens, B.E. (2017) Electronic Media Time and Sedentary Behaviors in Children: Findings from the Built Environment and Active Play Study in the Washington DC Area. Preventive Medicine Reports, 6, 149-156. https://doi.org/10.1016/j.pmedr.2017.02.021

[37] Ferreira, R., Rombaldi, A., Ricardo, L., Hallal, P. and Azevedo, M. (2016) Prevalence of Sedentary Behavior and Its Correlates among Primary and Secondary School Students. Revista Paulista De Pediatria (English Edition), 34, 56-63.

https://doi.org/10.1016/j.rppede.2015.09.002 